\title{
La disciplina del cuerpo en la relación laboral: límites al poder directivo y apuntes desde la jurisprudencia y legislación en Brasil ${ }^{*}$ Discipline of the body in the labour relationship: Limits on board power and notes from jurisprudence and legislation in Brazil
}

\author{
FELIPE GOMES DA SILVA VASCONCELLOS ${ }^{1}$ \\ Felipe.gsv@gmail.com
}

\section{RESUMEN}

El artículo analizó, a la luz del derecho laboral, los límites al poder del empleador en la relación laboral, particularmente respecto de las exigencias a la trabajadora o al trabajador, que van más allá de la pura utilización de la fuerza de trabajo y buscan, por medio de la disciplina del cuerpo, con la sumisión y sobreexplotación del trabajo en este contexto, la maximización del lucro. La disciplina del cuerpo, actualmente, se da en el lugar de trabajo tanto por medio de conductas que niegan la autonomía, la dignidad y la integridad física y psicológica de la trabajadora o trabajador - por ejemplo, las hipótesis del control del uso del baño, cacheos corporales o íntimos, técnicas motivacionales abusivas o el uso del polígrafo-, como por medio de conductas que se apropian de la discriminación política y social que ya existe en la sociedad y las reproduce al interior de las empresas, fábricas, oficinas, etc., como forma de aprovecharse de los prejuicios y patrones establecidos para la ampliación del lucro, mediante suposiciones de imposición de un patrón estético o cultural. El artículo pretendió, con base en la identificación de la disciplina del cuerpo en casos concretos, ofrecer un instrumental teórico objetivo para la caracterización de la conducta abusiva del empleador en la relación laboral, más allá, por lo tanto, de la casuística o de la ponderación de principios.

PALABRAS CLAVE: disciplina del cuerpo, dignidad humana, discriminación, poder directivo.

\begin{abstract}
The article analyzes, through Labor Law, the limits to the power of the employer in the labor relation, particularly due to their demands on workers, that go beyond the pure use of the labor force and seek, through the discipline of the body, with the submission and overexploitation of work in this context, the maximization of profit. The discipline of the body, today, occurs both through behaviors that deny the autonomy, dignity and physical and psychological integrity of the workers in the workplace, such as the control of the use of the bathroom, physical or intimate searches in the workplace, abusive motivational techniques or the use of the polygraph, as well as through behaviors that appropriate political and social discrimination that already exists in society and reproduces them in the workplace, as a way of taking advantage of the prejudices and patterns established for the increase of profit, here are hypotheses of imposing an aesthetic or cultural pattern in the workplace. The article aims, based on the identification of the discipline of the body in specific cases, to provide an objective theoretical instrument for the characterization of the abusive behavior of the employer in the employment relationship, beyond, therefore, casuistry or Weighting principles.
\end{abstract}

KEYWORDS: discipline of the body, human dignity, discrimination, executive power.

Fecha de recepción: 2016/09/21 - Fecha de evaluación: 2016/10/25 - Fecha de aprobación: 2016/11/30

* Cómo citar este artículo: Gomes da Silva Vasconcellos, F. (Enero-Junio de 2017). La disciplina del cuerpo en la relación laboral: límites al poder directivo y apuntes desde la jurisprudencia y legislación en Brasil. Criterio Jurídico Garantista, 10(16), 106-123.

1. Profesor de Derecho Laboral en el posgrado del Centro Universitario Padre Anchieta (UniAnchieta). Abogado de sindicatos, máster en Derecho Laboral por la Universidad de São Paulo. Investigador en el equipo de investigación Trabajo y Capital (USP). 


\title{
La disciplina del cuerpo en la relación laboral: límites al poder directivo y apuntes desde la jurisprudencia y legislación en Brasil
}

\author{
FELIPE GOMES DA SILVA VASCONCELLOS
}

\begin{abstract}
SUMARIO
Introducción - I. LA DISCIPLINA DE LA FUERZA DE TRABAJO Y DEL CUERPO - II. EL PODER DEL EMPLEADOR: PODER DIRECTIVO Y LÍMITES AL EJERCICIO DE ESE PODER - III. LA DISCIPLINA DEL CUERPO COMO ACTO OFENSIVO DE LA DIGNIDAD E INTEGRIDAD FÍSICA Y PSICOLÓGICA DE LA TRABAJADORA Y DEL TRABAJADOR - IV. LA DISCIPLINA DEL CUERPO COMO ACTO DE DISCRIMINACIÓN - V. CONCLUSIÓN - Referencias.
\end{abstract}

\section{Introducción}

El artículo analiza, a la luz del derecho laboral, los límites al poder del empleador en la relación laboral, particularmente en lo relativo a las exigencias a la trabajadora o al trabajador que van más allá de la pura utilización de la fuerza de trabajo y buscan, por medio de la disciplina del cuerpo, con la sumisión y sobreexplotación del trabajo, la maximización del lucro.

La disciplina del cuerpo, actualmente, se da en el lugar de trabajo tanto por medio de conductas que niegan la autonomía, la dignidad y la integridad física y psicológica de la trabajadora o trabajador - por ejemplo las hipótesis del control del uso del baño, cacheos corporales o íntimos, técnicas motivacionales abusivas o el uso del polígrafo-, como por medio de conductas que se apropian de la discriminación política y social que ya existe en la sociedad y las reproduce al interior de los lugares de trabajo, como forma de aprovecharse de los prejuicios y patrones establecidos para la ampliación del lucro, mediante hipótesis de imposición de un patrón estético o cultural.

Aunque las discusiones que involucran la disciplina del cuerpo en la sociedad contemporánea no sean nuevas, la apropiación del debate desde el instrumental jurídico puede ser útil para la comprensión y análisis de casos concretos, normalmente interpretados desde la casuística y ponderación de principios.

En ese contexto, se analiza, en primer lugar, de qué forma se constituye la disciplina del cuerpo como un nuevo espacio de reproducción de las contradicciones del capital; en segundo lugar, la posición de la doctrina laboral respecto del poder del empleador, su concepto y límites delante de 
una nueva racionalidad del derecho que permitió la construcción del derecho laboral. Al fin, busca el instrumental jurídico existente que permite enfrentar esta nueva forma de sobreexplotación del trabajo, identificando la disciplina del cuerpo en casos concretos y analizando la jurisprudencia y legislación en Brasil.

Así, se observan tanto casos que involucren la ofensa a la dignidad humana y la integridad física y psicológica de trabajadoras y trabajadores considerados desde su posición en el proceso productivo, como casos que comprendan la reproducción de perjuicios sociales en los lugares de trabajo, tratados aquí desde la condición como mujer, hombre, negra o negro, homosexual, transgénero y desde otras identidades que impli-

108 quen, por esta vía, la incursión de una coerción sobre los cuerpos.

La división de instancias es puramente para fines didácticos y de análisis; a la vez, la interseccionalidad de los espacios se muestra presente en todas las instancias, siendo cierto que la discriminación social se profundiza cuando son considerados trabajadores y trabajadoras en sus puestos de trabajo.

\section{La disciplina de la fuerza de trabajo y del cuerpo}

Para Maneghetti y Sampaio (2016), la disciplina no es nada más que "una modalidad de ejercicio del poder o una tecnología de poder, es decir, una manera específica según la cual unos ejercen el poder sobre los otros" (p. 136). En palabras de Foucault (1987, p. 119):

La disciplina produce así cuerpos sumisos y ejercitados, cuerpos 'dóciles'. La disciplina aumenta las fuerzas del cuerpo (en términos económicos de utilidad) y disminuye estas mismas fuerzas (en términos políticos de obediencia). En una palabra: disocia el poder del cuerpo; hace de él, por un lado, una 'aptitud', una capacidad que busca aumentar; y, por otro lado, invierte la energía, la potencia que podría resultar haciendo de ella [la disciplina ] una relación de sujeción estricta. Si la explotación económica aparta la fuerza y el producto del trabajo, decimos que la coerción disciplinar establece en el cuerpo el enlace coercitivo entre una aptitud aumentada y una dominación considerable.

A este respecto, la disciplina del cuerpo se comprende como inseparable de la propia disciplina de la fuerza de trabajo. No basta, por lo tanto, que el trabajador sea separado de los medios de producción necesarios para la realización de su trabajo, es esencial que su propia existencia y corporeidad esté sometida a los comandos del capital.

La dinámica de esa sumisión, sin embargo, no surge de la autonomía privada de la voluntad de las partes en un contrato de trabajo, sino por medio de la violencia.

De hecho, aunque el pensamiento iluminista del siglo XVIII sea todavía profesado en la academia en pleno siglo XXI, que insiste en evidenciar la primacía de la voluntad libre y soberana del individuo aislado de las relaciones sociales que lo involucran, ${ }^{2}$ la constitución del trabajador

2. La idea de que el contrato de trabajo es expresión de la autonomía privada de la voluntad, que se revela libre de coerción y entre partes iguales, se asemeja, ideológicamente, a los postulados iluministas de formación del Estado moderno. John Locke (1632-1704) 
asalariado libre, en las palabras de Marx (2013), "están grabadas en los anales de la humanidad con rasgos de sangre y fuego"(p. 787).

El trabajador libre, para que así se constituyera, exigió, en primer lugar, que fuera liberado (expropiado) de todos los medios y condiciones que poseía para la realización de su trabajo, de forma que su única alternativa fuera la venta de su fuerza de trabajo a los detenedores de los medios de producción. Para la transformación del dinero y de las mercancías en capital, Marx apunta ser necesarias dos especies bien distintas de poseedores: por un lado, los poseedores de dinero y de los medios de producción y, por otro lado, los trabajadores libres, vendedores de su propia fuerza de trabajo. Respecto de la libertad del trabajador, Marx (2013) escribe:

Trabajadores libres en el doble sentido de que ni integran directamente los medios de producción, como esclavos o siervos, etc., ni les pertenecen medios de producción, como en el caso, por ejemplo, del campesino que trabaja por su cuenta, etc., pero están, antes, libres y disociados de estos medios de producción. (p. 786).

Conforme al mismo autor, el "proceso que crea la relación capitalista no puede ser otro que el proceso de separación entre el trabajador y la propiedad de las condiciones de la realización del trabajo" (Marx, 2013, p. 786). Y continúa precisando:

El movimiento histórico que transforma a los productores en trabajadores asalariados se muestra, por un lado, como liberación de estos trabajadores de la servidumbre y de la coacción corporativa $(. .$.$) En cambio, estos recién liberados solo se$ convierten en vendedores de sí mismos después que les roban todos sus medios de producción, así como todas las garantías de su existencia que las viejas instituciones feudales les ofrecían. (Marx, 2013, p. 787).

Dicho proceso pasa por crear las condiciones del desarrollo del capital, particularmente por medio de la disciplina de la fuerza de trabajo, lo que se ha hecho por medio o a pesar de la ley, y siempre con el uso de la fuerza.

En este sentido es que los cercamientos - expropiación de tierra de los campesinos, de la Iglesia o comunales - son utilizados en gran escala en Inglaterra como acto preparatorio para el desarrollo capitalista, primeramente, en contra de la ley y, después, como política de Estado.

Vimos cómo la violencia y usurpación de la propiedad comunal, en general acompañada de la transformación de las tierras de cultivo en pasturas, tiene inicio en el final del siglo XV y prosigue durante el siglo XVI. En esta época, sin embargo, el proceso se efectiva por medio de actos indi-

y Jean Jacques Rousseau (1712-1778) son dos exponentes de esa idea del contrato social en el período iluminista. Sin embargo, de las particularidades de la teoría de cada uno hay un punto en común en la medida en que, para los dos, los individuos son seres presociales, es decir, se constituyen como entidades aisladas, antes de la formación de la sociedad y del Estado. De la misma forma, las teorías contractualistas del contrato de trabajo apuntan a la primacía del individuo sobre las relaciones colectivas, y consideran un individuo anterior a la "sociedad del trabajo libre/relación laboral capitalista", que la constituye por medio de un contrato social de trabajo. Sobre los autores iluministas cf. Mascaro (2012) y respecto a las teorías contractualistas tradicional y moderna, y teorías acontratualistas de la relación laboral, ver Delgado (2014, pp. 310-322).

Criterio Jurídico Garantista. (Ene.-Jun. de 2017). Vol. 10, n. ${ }^{\circ}$ 16, 106-123. ISSN: 2145-3381. Bogotá: Universidad Autónoma de Colombia. 
viduales de violencia, en contra de los cuales la legislación actuó en vano, durante 150 años. El proceso alcanzado en el siglo XVIII está en que la propia ley se convierte, ahora, en el vehículo del robo de las tierras del pueblo, sin embargo los grandes arrendatarios también emplean paralelamente sus pequeños e independientes métodos privados. La forma parlamentaria del robo son las Bills for Inclosures of Commons (leyes para el cercamiento de la tierra comunal). (Marx, 2013, p. 796$)$.

Esto es lo que llamamos el período de la acumulación primitiva del capital. Dicha política reducía las alternativas de los campesinos, que se veían obligados a migrar a las ciudades, y a ajustarse al trabajo asalariado libre. A aquellos que no se ajustaban —el crecimiento del número

110 de la población de calle y sin ocupación creció considerablemente en el período- la carga de la violencia institucional recaía sobre sus espaldas, con diversas leyes en contra de la población de la calle, que llegaban hasta permitir la esclavitud de quienes no trabajaban, azotes y, al fin, en casos de reincidencia, la ejecución. Solo para no quedarnos sin un ejemplo,

Elizabeth, 1572: pobladores de calle sin licencia y con más de 14 años de edad deben ser severamente azotados y tener la oreja izquierda marcada con hierro, en caso de que nadie los quiera tomar a servicio por 2 años; en caso de reincidencia, y más de 18 años de edad, deben ser ejecutados, en caso que nadie los quiera tomar a su servicio por 2 años; en la segunda reincidencia, serán ejecutados sin misericordia, como traidores al Estado. (Marx, 2013, p. 807). ${ }^{3}$
La libertad del trabajo, por lo tanto, se dio por medio de un nuevo aprisionamiento, ahora del trabajo por el capital. A pesar de la apariencia contractual ideal, en la forma profesada por un Iluminismo moderno en que prima el individuo como sujeto de derechos, libre e igual a los demás seres, la generalización del trabajo asalariado libre y el así nombrado contrato de trabajo, ocultan relaciones de desigualdad material y de clase que solo el análisis materialista de la historia nos permite demostrar.

En ese contexto, la disciplina de la fuerza de trabajo se constituyó como disciplina del cuerpo, en la medida en que la venta de la fuerza de trabajo se vislumbró inseparable de los elementos corpóreos que la constituyen. Ese movimiento, todavía, no se dio libre de resistencia. Todo el desarrollo del capital es marcado por importantes insurgencias de la clase trabajadora como sujeto político transformador. Esa dinámica de luchas y resistencias pasa, a lo largo de la historia, por diversas instancias de las relaciones sociales y sufre, en los años 1960 y 1970, una proliferación de espacios de reacción que entran a considerar, más allá de los elementos económicos, las cuestiones de género, identidad étnica, racial, sexual y otros que amplían las posibilidades de resistencia.

Aunque ese proceso no se dé libre de contradicciones, a la vez que las afirmaciones de identidad del cuerpo son, ellas mismas, capitalizadas y mercantilizadas; el facto es que el cuerpo se establece como un espacio de lucha y afirmación de la clase

3. Cf. al respecto, Marx (2013, pp. 805-813). 
trabajadora, en sus distintos aspectos de género, raza, orientación sexual y de clase trabajadora en sí misma.

De hecho, el capital reduce todo y todos a la condición de pura mercancía. La objetivación del trabajo nos impide revelar la esencia del movimiento del capital. Cuando ese movimiento sufre obstáculos materiales a su expansión, sea por medio de la imposibilidad de desarrollar las fuerzas productivas, o porque la ampliación de la jornada laboral enfrenta una barrera en la lucha de clases, el capital busca todas las fisuras del tejido social para su reproducción. En ese contexto, el cuerpo se revela como un espacio de lucha. Defenderlo, por lo tanto, es esencial para garantizar la dignidad y la propia existencia de la clase trabajadora.

\section{El poder del empleador: poder directivo y límites al ejercicio de ese poder}

Aunque la disciplina de la fuerza de trabajo esté asociada en un primer momento a la disciplina del cuerpo, las contradicciones del desarrollo del capital, particularmente los límites impuestos por la lucha de clases, hacen emerger diversos espacios de resistencia, entre ellos, el propio cuerpo.

El poder absoluto del empleador en los lugares de trabajo sufre, pues, diversas incursiones, tanto por medio de la fuerza de los trabajadores como por parte de la normativa estatal. La dirección de la empresa, en este sentido, no es mirada desde el punto de vista único y exclusivo de los intereses del propietario de la empresa, sino, ante todo, de su finalidad social.

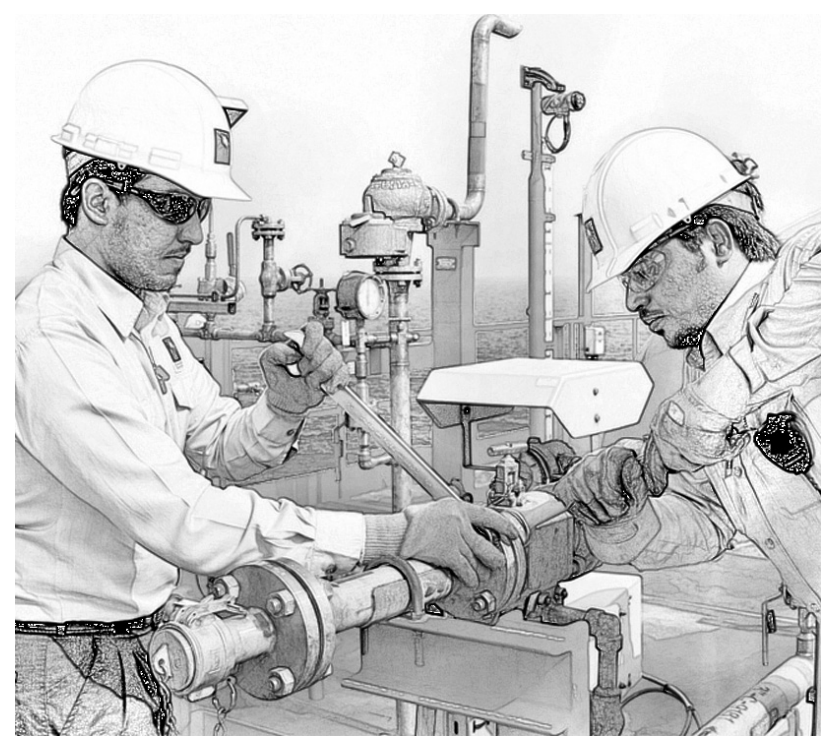

La disciplina de la fuerza de trabajo se constituyó como disciplina del cuerpo, en la medida en que la venta de la fuerza de trabajo se vislumbró inseparable de los elementos corpóreos que la constituyen. Ese movimiento, todavía, no se dio libre de resistencia. Todo el desarrollo del capital es marcado por importantes insurgencias de la clase trabajadora como sujeto político transformador.

A este respecto, debemos hacer el análisis de la doctrina laboral sobre el poder del empleador en los lugares de trabajo, su concepto, aspectos y límites establecidos a su ejercicio, para, en un segundo momento (puntos III y IV del artículo), ajustar estos límites desde la perspectiva de la disciplina del cuerpo.

Para Delgado (2014), el poder del empleador se divide en poder directivo, poder reglamentario, poder de fiscalización y poder disciplinario, aunque solo las formas de poder directivo y disciplinario alcancen 
"amplitud, consistencia e identidad propias" (p. 685), que justifiquen su análisis como modalidades del poder laboral.

El poder directivo es definido por Delgado como el conjunto de prerrogativas "dirigidas a la organización de la estructura y espacio empresariales internos, inclusive el proceso de trabajo adoptado en el establecimiento y en la empresa, con la especificación y orientación cotidianas en lo que respecta a la prestación de servicios" (2014, p. 686). Expresión externa del poder directivo son los reglamentos y metas directivas establecidas por la empresa.

El poder de fiscalización, a su vez, también se enmarca como una expresión del poder directivo,

112 posibilitando el "acompañamiento continuo de la prestación laboral y la propia vigilancia realizada a lo largo del espacio empresarial interno"(Delgado, 2014, p. 688). Por fin, el poder disciplinario se manifiesta en las prerrogativas "dirigidas a propiciar la imposición de sanciones a los empleados en caso de incumplimiento de sus obligaciones contractuales" (Delgado, 2014, p. 690).

Como se observa, la doctrina laboral tradicional reconoce y legitima el poder del empleador en las relaciones laborales, pero no sin límites. De hecho, las formas de ejercicio de ese poder encuentran límites objetivos, tanto desde el punto de vista vertical, es decir, por medio de normas de orden público estatales que aspiran a resguardar la protección de los derechos humanos en la relación laboral, como horizontal, garantizando el derecho de resistencia, por medio de acciones colectivas o individuales que puedan hacer frente al abuso del poder directivo y disciplinario del empleador, así como promover nuevos derechos con el fin de mejorar su condición social.

Efectivamente, si consideramos la compañía como la actividad económica organizada y local donde el trabajador ejerce su actividad, contribuyendo directamente para el desarrollo del producto de su trabajo; y que el propio lucro del propietario de la empresa es extraído del trabajo no pago a ese empleado o la plusvalía ${ }^{4}$, no es posible admitir el ejercicio del poder unilateral del empleador en las relaciones laborales, particularmente cuando estas tratan de la dirección del trabajo ejecutado, formas y medios de ejecución y el poder disciplinario.

La racionalidad social del derecho, ${ }^{5}$ que se expresa de forma más contundente en el derecho

4. "La fuerza de trabajo posee una calidad única, un trazo que la diferencia de todas las otras mercancías: ella crea valor - cuando es utilizada, ella produce más valor que lo necesario para reproducirla, ella genera un valor superior a su coste. Y es justo ahí que se encuentra el secreto de la producción capitalista: el capitalista paga al trabajador el equivalente al valor de cambio de su fuerza de trabajo y no el valor creado por ella en su utilización (uso) - y este último es mayor que el primero. El capitalista compra la fuerza de trabajo por su valor de cambio y se apropia de todo su valor de uso". Para un análisis introductorio, cf. Netto y Braz (2012, p. 113).

5. La racionalidad social del derecho se refiere a un proceso de cambio en los fundamentos de la teoría general del derecho, hasta entonces de carácter liberal y que pasa, a lo largo del siglo XX, a ser pensado desde su finalidad social, de forma que los derechos individuales absolutos e intocables, como la propiedad privada (art. $5^{\circ}$, XXIII, CRFB/88), el contrato (art. 42 1, CCB/2002) y la empresa (art. 47, Lei n. 11.101/2005), son comprendidos y garantizados desde que cumplan su función social. El derecho laboral, 
laboral, no permite un análisis del contrato laboral y de las relaciones laborales separadas de la finalidad social que las constituyen. El hecho de ser propietario de una compañía no le da el derecho al empleador de negar la existencia y el rol de los trabajadores en los lugares de trabajo, particularmente desde una comprensión democrática de estas mismas relaciones, es decir, volcada no solo a la protección, sino a la evolución de las condiciones sociales que se presentan.

Los límites a ese poder, por lo tanto, son claros, y expresos en tratados y convenios internacionales. Particularmente, en Brasil, estos límites están expresos no solo en la Constitución de la República Federativa de Brasil de 1988 (CRFB/88), sino en la ley ordinaria. Por ejemplo, la necesidad de democracia en las relaciones laborales permite a los trabajadores un representante en los lugares de trabajo, en las empresas con más de doscientos empleados (art. 11, CRFB/88), mecanismo hábil para que, colectivamente, los trabajadores puedan defender y promover nuevos derechos en las relaciones laborales.

Desde el punto de vista de la ley ordinaria, el poder directivo del empleador también es limitado, entre otras normas, ${ }^{6}$ por medio del artículo 163 de la Consolidación de las Leyes del Trabajo
(Consolidação das leis do trabalho (CLT) - DecretoLei ${ }^{\circ}{ }^{0} 5.452$, de $1^{\circ}$ de maio de 1943) ${ }^{7}$ y la Norma Reglamentaría n. ${ }^{\circ} 5$, que constituyó la Comisión Interna de Prevención de Accidentes (CIPA), con la participación de trabajadores electos entre sus pares y otros indicados por la empresa, con el fin de prevenir accidentes y enfermedades derivadas del trabajo, así como promover la salud del trabajador. Sobre este particular debemos observar que los representantes electos por los trabajadores tienen estabilidad en el empleo, desde el registro de la candidatura hasta un año después de terminado el mandato.

Para Delgado (2014), la CRFB de 1988 trazó las reglas y principios rectores en el análisis de los casos concretos, de forma que "rechazó las conductas de fiscalización y control de la prestación laboral que perjudiquen la libertad y dignidad elementales de la persona del trabajador"(p.689), o del conjunto de los trabajadores, considerados desde su colectividad, podríamos añadir.

De hecho, la CRFB de 1988 instituye en su preámbulo, un

Estado Democrático, destinado a asegurar el ejercicio de los derechos sociales e individuales, la libertad, la seguridad, el bien-estar, el desarrollo, la igualdad y la justicia como valores supremos de una socie-

en este sentido, es expresión mayor de esa racionalidad social, y es definido por Souto Maior como "el instrumental jurídico que incentiva el desarrollo de prácticas emancipadoras desde una perspectiva crítica de la realidad, poniéndole la relación del hombre con el trabajo en el contexto de la sociedad capitalista", o como "instrumental de justicia social”. Sobre la racionalidad social del derecho cf. Souto Maior (2011, p. 580).

6. La limitación de la jornada laboral; las normas de protección especial al trabajo de la mujer, de los niños y adolescentes; las normas reglamentarias de protección a la salud de las trabajadoras y trabajadores; la estabilidad provisional; solo para citar algunos ejemplos, son todas normas que limitan el poder directivo absoluto del empleador.

7. Todas las referencias a la CLT fueron extraídas del sitio http://www.planalto.gov.br/ccivil_03/decreto-lei/Del5452.htm 
La disciplina del cuerpo en la relación laboral apunta dos instancias, que son separadas solo para fines didácticos, pues normalmente se interrelacionan y son interdependientes: la primera, por medio de la negación de la autonomía individual de la trabajadora o trabajador, y la segunda desde la reproducción de perjuicios sociales en los lugares de trabajo, con imposición de un patrón estético, cultural o de otra naturaleza.

\section{4}

dad fraterna, pluralista y sin perjuicios, basada en la armonía social. [Cursivas en el original].

La dignidad humana pasa a ser un fundamento del Estado Democrático de Derecho (art. 1º, III, $\mathrm{CRFB}$ /88), que tiene como objetivos construir una sociedad libre, justa y solidaria (art. $3^{\circ}$, I, CRFB/88), además de promover el bien de todos, sin perjuicios de origen, raza, sexo, color, edad, y cualquiera otras formas de discriminación (art. $3^{\circ}$, IV, CRFB/88).

En su artículo $5^{\circ}$, caput, a su vez, consagra la igualdad de todos delante de la ley, garantizando la inviolabilidad del derecho a la vida, a la libertad, a la igualdad, a la seguridad y a la propiedad, en los términos de sus incisos, que afirman, además de otras cosas, que "nadie será sometido a tortura, ni a trato deshumano o degradante" (art. $5^{\circ}$, II, $\mathrm{CRFB} / 88$ ); y que "son inviolables la intimidad, la vida privada, el honor y la imagen de las perso- nas, asegurando el derecho a la indemnización por el daño moral o material derivado de dicha violación" (art. 5 $, \mathrm{C}, \mathrm{CRFB} / 88$ ); que "la práctica del racismo constituye crimen sin fianza e imprescriptible"; además de otros que aspiran a resguardar la integridad física y psicológica del trabajador.

En este sentido, se destaca la "prohibición de la diferencia de sueldos, de ejercicio de funciones y de criterios de admisión debido a sexo, edad, color o estado civil" (art. $7^{\circ}, \mathrm{XXX}, \mathrm{CRFB} / 88$ ); la "prohibición de cualquier discriminación en cuanto al sueldo y criterios de admisión del trabajador con discapacidad" (art. $7^{\circ}$, XXXI, CRFB/88), y el que se garantiza el derecho de huelga, "incumbiendo a los trabajadores decidir sobre la oportunidad de ejercerlo y sobre los intereses que deban por medio de eso defender" (art. $9^{\circ}$, CRFB/88).

La comprensión de democracia como un derecho humano aplicable no solo a la organización política del Estado, sino a todas las instancias sociales, permite ver la mitigación y los límites del poder laboral dicho arriba. Sin embargo, no basta una nueva ley o una nueva comprensión racional del derecho para que las relacionales sociales se cambien. La dinámica concreta del modo de producción capitalista, que visa reducir el derecho laboral a un costo de producción, acaba por impedir concretamente la efectividad de esa protección. No obstante, dado que la pura actividad jurisdiccional no es apta para resolver los problemas puestos, se comprende que un análisis más objetivo de estos límites constitucionales, ordinarios o internacionales, puede ser útil en el enfrentamiento de casos concretos en los cuales se observe el abuso del poder del empleador desde 
la perspectiva propuesta, es decir, de la disciplina del cuerpo.

III. La disciplina del cuerpo como acto ofensivo de la dignidad e integridad física y psicológica de la trabajadora y del trabajador

Como se observa, el poder directivo del empleador encuentra límites muy evidentes en normas constitucionales y ordinarias que resguardan los derechos humanos en las relaciones laborales. En este sentido, se analiza a continuación el instrumental jurídico de protección a las trabajadoras y trabajadores desde la perspectiva del cuerpo.

Como se dijo arriba, la disciplina del cuerpo en la relación laboral apunta dos instancias, que son separadas solo para fines didácticos, pues normalmente se interrelacionan y son interdependientes: la primera, por medio de la negación de la autonomía individual de la trabajadora o trabajador, y la segunda desde la reproducción de perjuicios sociales en los lugares de trabajo, con imposición de un patrón estético, cultural o de otra naturaleza.

La negación de la autonomía individual de la trabajadora o trabajador, con daños a su integridad física o psicológica se expresa, sin perjuicio de otras formas no abordadas, por medio del control del uso del baño, el cacheo/registro corporal o íntimo en los lugares de trabajo, técnicas motivacionales abusivas o el uso del polígrafo. En este artículo se analiza específicamente la posición de la Corte Superior de Trabajo de Brasil frente a los casos mencionados, su motivación de decidir, y de qué forma la disciplina del cuerpo puede servir como punto de referencia para los casos concretos.

En lo que se refiriere al control del uso del baño, la jurisprudencia de la Corte Superior de Trabajo de Brasil ha comprendido que la conducta, por sí misma, ya expresa el ejercicio abusivo del poder directivo, implicando violación a la dignidad humana (art. $1^{\circ}$, III, CRFB/88). ${ }^{8}$ Los fundamentos

8. Solo los fundamentos de la decisión fueron traducidos al español, de forma libre por el autor. Para más claridad se destacan en cursivas.

AGRAVO DE INSTRUMENTO. INDENIZAÇÃO POR DANOS MORAIS. RESTRIÇÃO E CONTROLE NO USO DO BANHEIRO. Caracterizada possível violação do art. 1o, III, da Constituição Federal, cabível o processamento do recurso de revista. Agravo de instrumento provido. RECURSO DE REVISTA. INDENIZAÇÃO POR DANOS MORAIS. RESTRIÇÃO E CONTROLE NO USO DO BANHEIRO. La restricción del uso del baño por la empresa no puede ser considerada conducta razonable, pues configura violación a la dignidad de la persona humana y a la privacidad, así como abuso del poder directivo del empleador. La conducta patronal, caracterizada por la restricción y fiscalización del uso del baño, expone el trabajador a constreñimiento innecesario, permitiendo la condenación al pago de la indemnización por daño moral. Recurso de revista conhecido e provido. (RR-129500-56.2013.5.13.0009, Relator Ministro: Augusto César Leite de Carvalho, Data de julgamento: 24/09/2014, 6 a Turma, Data de Publicação: 10/10/2014). RECURSO DE EMBARGOS. DANO MORAL - CARACTERIZAÇÃO - RESTRIÇÃO AO USO DO TOALETE - APLICAÇÃO DA SÚMULA/TST No 126. Como se observa, en entendimiento adoptado por la Turma es en el sentido de que el hecho de la empresa de controlar el tiempo de utilización del baño, por si mismo, es suficiente para generar el derecho a la reparación por daños morales. Assim, a par da discussão acerca da configuração, ou não, de dano moral na presente hipótese, tendo constado no acórdão em recurso 
del fallo evidencian la violación a la dignidad humana y a la privacidad, revelando un riesgo en el medio ambiente laboral y en la salud física de las empleadas y empleados.

Esto es una evidente incursión sobre el cuerpo de la trabajadora y trabajador, que niega su existencia autónoma y necesidades fisiológicas, intentando disciplinarlas con el único fin de extraer un beneficio económico, y una pretendida mayor productividad de la fuerza de trabajo. La exacerbación de esta conducta puede llegar hasta la exigencia del uso de pañales a los trabajadores para que no tengan que ir al baño, como denunció Ferdman (2016) en un periódico de Estados Unidos.
En lo que se refiere a los cacheos corporales o intimos, la doctrina laboral también repudia dicha práctica, pues es atentatoria de la dignidad humana y de la intimidad de la trabajadora o trabajador, aunque presente una mitigación desde lo que se entiende por cacheo impersonal. Así es que mientras el cacheo intimo incide sobre el cuerpo de los individuos, por medio de contacto físico, el cacheo impersonal recae sobre las posesiones de las personas, sin contacto físico, como por ejemplo sobre las mochilas o carteras. Según la Corte Superior de Trabajo de Brasil el cacheo impersonal en los bienes de las personas, sin contacto físico, no se caracterizaría como un abuso del poder directivo. ${ }^{9}$

ordinário que havia controle das -idas ao banheiro-, a conclusão adotada pela Turma não contrariou a Súmula/TST no 126, na medida em que se ateve a dar o enquadramento jurídico à situação exposta ao seu julgamento. Recurso de embargos conhecido e desprovido. (E-RR - 134200-07.2008.5.18.0011, Relator Ministro: Renato de Lacerda Paiva, Data de Julgamento: 07/03/2013, Subseção I Especializada em Dissídios Individuais, Data de Publicação: DEJT 15/03/2013).

RECURSO DE EMBARGOS. DANO MORAL. SUBMISSÃO DE EMPREGADA AO CONTROLE DE HORÁRIO PARA UTILIZAÇÃO DO BANHEIRO. INDENIZAÇÃO DEVIDA. La dignidad es la piedra angular de todos los otros derechos y libertades de la persona humana: todas las personas son iguales, deben ser tratadas con respeto e integridad, y la violación de este principio debe de ser sancionada por la ley. Por el principio de la dignidad humana cada ser humano posee un derecho intrínseco e inherente que debe de ser respetado. Todas las conductas abusivas, que se repitan a lo largo del tiempo y cuyo objeto atente en contra del SER humano, de su dignidad o su integridad física o psíquica, durante la ejecución del trabajo deben de ser sancionadas pues ponen en riesgo el medio ambiente laboral y la salud fisica del empleado. Un medio ambiente intimidador, hostil, degradante, humillante u ofensivo que se manifieste por palabras, intimidaciones, actos o gestos o escritos unilaterales deben de ser contenidos por exponer a sufrimiento fisico o situaciones humillantes a los empleados. En ese contexto, el empleador debe hacer todo lo posible para prevenir el daño psicosocial provocado en el trabajo. En la hipótesis del proceso, se debe tener en miente que no todos los trabajadores logran soportar sin incomodidad, el tiempo de espera para el uso del baño, sin que este acto no represente una agresión psicológica (y fisiológica). La indemnización en cuestión tiene por objetivo suscitar la discusión sobre el papel del empleador en la garantía de los derechos sociales fundamentales mínimos a que hace jus el trabajador. Embargos conhecidos e desprovidos. (E-RR - 65900-97.2006.5.01.0055, Relator Ministro: Aloysio Corrêa da Veiga, Data de Julgamento: 10/02/2011, Subseção I Especializada em Dissídios Individuais, Data de Publicação: DEJT 25/02/2011).

9. INDENIZAÇÃO POR DANO MORAL. REVISTA IMPESSOAL DE BOLSAS E SACOLAS. SEM CONTATO FÍSICO. El cacheo consistente en la verificación del contenido de mochilas, carteras, etc. de los empleados, de modo indiscriminado y sin contacto fisico o cacheo intimo, por sí mismo, no caracteriza ofensa al honor y a la intimidad de la persona capaz de generar daño moral sujeto de reparación. Recurso de Embargos de que se conhece e a que se dá provimento. (E-RR - 553-75.20 10.5.04.0029, Relator Ministro: João Batista Brito Pereira, Data de Julgamento: 25/9/2014, Subseção I Especializada em Dissídios Individuais, DEJT 3/10/2014). [Cursivas añadidas]. 
Aunque las normas y principios constitucionales sean suficientes para vedar dicha práctica, pues establecen el principio da la dignidad humana (art. $1^{\circ}$, III, CRFB/88) y la inviolabilidad de la "intimidad, la vida privada, el honor, y la imagen de las personas, asegurando el derecho a la indemnización por el daño material o moral derivado de dicha violación” (art. $5^{\circ}, \mathrm{x}, \mathrm{CRFB} / 88$ ), la ley ordinaria prevé expresamente el repudio al cacheo íntimo.

La Ley n. ${ }^{\circ}$ 9.799/1999, en este sentido, incluyó el artículo 373-A, de la CLT y vedó expresamente en su inciso VI el cacheo íntimo del empleador o sus agentes en las empleadas. Recientemente, se reiteró la prohibición de la conducta a las empresas privadas, incluyendo ahí la administración pública

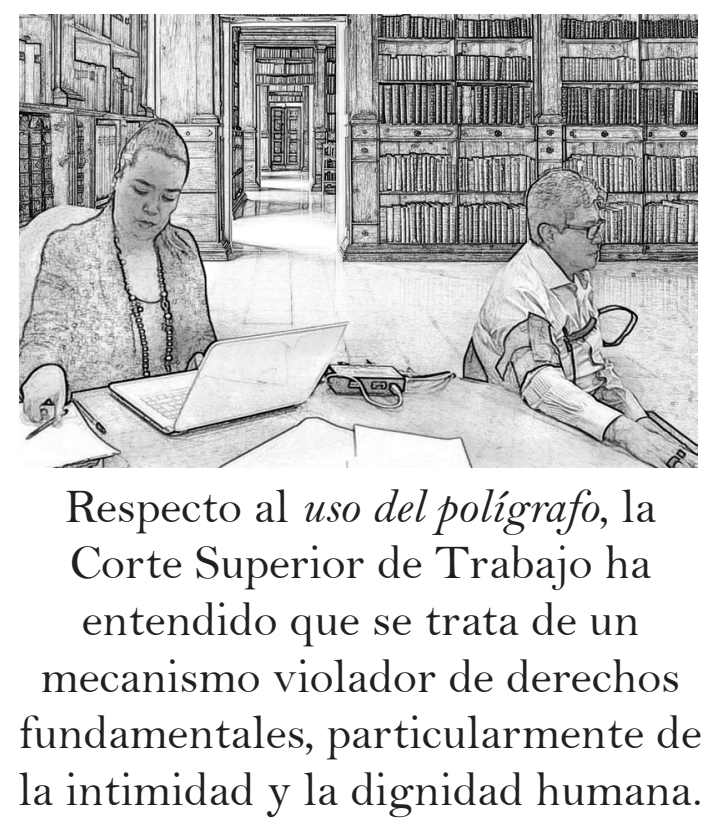
directa e indirecta, por medio de la Ley n. ${ }^{\circ} 13.271$ de 15 de abril de 2016, que dice en su artículo $1-^{\circ}$ : "Las empresas privadas, los órganos y entidades de la administración pública directa e indirecta, quedan prohibidos de adoptar cualquier práctica de cacheo íntimo de sus empleadas o servidoras y clientes del sexo femenino".

Sin embargo, hay que criticar tanto lo dispuesto en la ley como el posicionamiento de la jurisprudencia de la Corte Superior de Trabajo, por hacer la distinción entre el cacheo íntimo y el cacheo impersonal, con el fin de mitigar el derecho a la intimidad y dignidad de las trabajadoras y trabajadores.

En primer lugar, hay que apartar la interpretación literal de que dicha prohibición solo se aplicaría a las mujeres. Las prácticas discriminatorias positivas solamente tienen espacio cuando visan promover políticas de igualdad entre hombres y mujeres, en particular si se destinan a corregir las distorsiones que afectan la formación profesional, el acceso al empleo y a las condiciones generales del trabajo de la mujer (art. 373-A, párrafo único, CLT). La discriminación en lo que se refiere al cacheo, por lo tanto, no queda en ninguna de estas hipótesis. Así que debemos partir de una hermenéutica constitucional que garantice la igualdad de todos, sin cualquier tipo de discriminación (art. $5^{\circ}$, caput, CRFB/88), para expandir la protección ordinaria tanto a los hombres como a las mujeres.

La distinción jurisprudencial, a su vez, desconsidera que el cacheo en las pertenencias personales de la trabajadora y trabajador, aunque sin contacto físico, representa una incursión sobre el cuerpo, que ultrapasa, por lo tanto, la pura utilización de la fuerza de trabajo. Es evidente que las pertenencias personales son extensión del cuerpo de las trabajadoras y trabajadores, de su intimidad, y pueden evidenciar hábitos o 
costumbres que no desean hacer públicos, además de ser tema de constreñimiento. De otra parte, el cacheo "impersonal", aunque adoptado de forma indiscriminada, revela una supuesta desconfianza de la relación laboral.

De hecho, aunque una pretendida "seguridad de la compañía” justifique desde el punto de vista del empleador el cacheo impersonal, este procedimiento jamás puede aceptarse por la ley y el sistema judicial. La identificación de la disciplina del cuerpo, aquí, es herramienta importante para la constatación de la violación de los derechos fundamentales, propiciando el repudio tanto al cacheo íntimo como al impersonal, independiente de la naturaleza de la actividad, particularmente cuando la tecnología ya permite medios hábiles y eficientes para garantizar la seguridad de las compañías.

Las técnicas motivacionales, igualmente, cuando avanzan para la apropiación del cuerpo de la trabajadora o trabajador, también deben ser repudiadas. En el ámbito de las normas de protección de la salud del trabajador en Brasil, la Norma Reglamentaria n. ${ }^{\circ} 17$, que trata de la ergonomía, en el anexo II (trabajo en telemarketing), punto 5.13, veda los métodos que causen acoso moral, miedo o constreñimiento, como por ejemplo la "exigencia de que los trabajadores usen, de forma permanente o temporaria, adornos, accesorios y vestimentas con el objetivo de punición, promoción o propaganda”.

En la Corte Superior de Trabajo de Brasil la práctica abusiva también es repudiada, particularmente aquella conocida como cheers, ${ }^{10}$ es decir, reuniones motivacionales en las cuales los empleados son obligados a cantar himnos de exaltación de la empresa o danzar junto a los demás empleados y empleadas o hasta los mismos clientes. Aquí también la identificación de la disciplina del cuerpo es una herramienta importante para la constatación del abuso patronal respecto del poder directivo. Obligar a los trabajadores y trabajadoras a entonar cánticos o danzar como método motivacional revela en realidad un acoso moral, particularmente por repercutir en un campo que traspasa la pura prestación de servicios.

Finalmente, respecto al uso del polígrafo, aunque no haya reglamentación de la materia en Brasil, la Corte Superior de Trabajo ha entendido que se trata de un mecanismo violador de derechos fundamentales, particularmente de la intimidad y la dignidad humana. ${ }^{11}$ Sin embargo, al juzgar sobre

10. RECURSO DE REVISTA. LEI No 13.015/2014. DANOS MORAIS. INDENIZAÇÃO. CHEERS. CÂNTICOS E DANÇAS MOTIVACIONAIS OBRIGATÓRIAS. CONFIGURAÇÃO DE LESÃO À HONRA E À DIGNIDADE DOS EMPREGADOS. Es violador del principio de la dignidad humana del trabajador el acto de la empresa que obliga a sus empleados a participar en reuniones motivacionales en las que los obreros son impelidos a aplaudir y entonar cánticos de exaltación a la empresa, además de ser obligados a rodar delante de sus compañeros. En la hipótesis del proceso, queda comprobado que el demandante era forzado a participar de dichas prácticas motivacionales. Recurso de Revista conhecido e não provido. (...) (RR - 391-43.2012.5.09.0006, Relator Desembargador Convocado: Marcelo Lamego Pertence, Data de Julgamento: 08/06/2016, $1^{\text {a }}$ Turma, Data de Publicação: DEJT 17/06/2016). [Cursivas añadidas].

11. RECURSO DE REVISTA. DANO MORAL DECORRENTE DE SUBMISSÃO DE EMPREGADO A TESTE DE POLÍGRAFO (DETECTOR DE MENTIRAS). Se trata de saber si la sumisión del autor a la prueba del polígrafo (detector de mentiras) caracteriza 
la materia, la Corte repudia dicha práctica por no estar comprobada su eficacia y no ser utilizada en el proceso penal. Es decir, a contrario sensu, lo que la Corte dice es que, una vez comprobada la eficacia, el procedimiento tendría respaldo en las relaciones laborales. Con la debida venia, la argumentación que mitiga la defensa de los derechos humanos en las relaciones laborales en virtud de su pretendida efectividad, solo debilita la protección de dichos derechos e incentiva su violación.

Aquí también la perspectiva del cuerpo puede servir como elemento objetivo para identificar prácticas que exceden el objeto del contrato de trabajo, más allá de la pura casuística o ponderación de principios fundamentales que, en realidad, no protegen ni realizan los derechos humanos en las relaciones laborales, propiciando inseguridad jurídica tanto a los trabajadores como a los empleadores.

Tratándose, pues, de incursión sobre la autonomía del cuerpo, viólase, por lo tanto, la dignidad humana (art. 1 ${ }^{\circ}$, III, CRFB/88), la intimidad, la vida privada, el honor y la imagen de las personas (art. $5^{\circ}, \mathrm{X}, \mathrm{CRFB} / 88$ ), y por eso debemos repudiar y punir de forma eficaz los casos identificados, $\mathrm{y}$ otros en los cuales se verifique la referida incursión.

\section{La disciplina del cuerpo como acto de discriminación}

Otra instancia de la disciplina del cuerpo, como se mencionó antes, recae sobre las hipótesis en las cuales se producen perjuicios sociales en los lugares de trabajo, al imponer un patrón estético, de género, de orientación sexual, raza, cultural o cualquier otro.

En ese contex to se investigó el caso de la empresa estadounidense minorista de ropas Abercrombie, que adoptaba una política visual (look policy), y un código de vestuario (dress code) extremadamente restrictivo y prejuicioso. Según el propio

constreñimiento apto de reparación civil por daños morales. En el caso concreto, es incontrovertido que el autor ejerció el cargo de agente de seguridad y que sus atribuciones eran de inspeccionar cargas y equipajes, así como compartimientos de aeronaves con la finalidad de verificar la existencia de drogas, explosivos o cualquier otro artefacto que pudiera poner en riesgo el avión. Fue registrado, aún, que la "prueba fue empleada para fines de admisión del demandante, así como para todos los demás trabajadores que se presentaran al puesto de agente de seguridad". El polígrafo comprende un aparato de registro de respuestas, utilizado para comprobar la veracidad de las informaciones recogidas de una persona que es interrogada. La finalidad del aparato es averiguar la posible ocurrencia de mentiras de la persona examinada en su testimonio. No hay previsión en el ordenamiento jurídico brasileño para el examen de polígrafo, pues invade la intimidad de los sometidos a el, una vez que ni siquiera es eficaz como medio de prueba en contra de los empleados, tampoco se tiene noticias de su utilización válida en el proceso penal en el cual sería, en caso de comprobarse su eficacia, de suma importancia. El resultado obtenido por el polígrafo es puramente estimado, no permitiendo un diagnóstico seguro concerniente a la idoneidad moral de la persona que va a ser contratada. Así, pues, una vez que no hay reglamentación y no comprobada su eficacia, se puede considerar que el uso del aparato puede herir otros derechos fundamentales, entre los cuales cabe citar la preservación de la intimidad y la dignidad del trabajador. Precedentes desta Corte. Conclui-se, portanto, que o uso do polígrafo constitui procedimento que afronta direito fundamental previsto na Constituição Federal, sendo devido o pagamento de indenização por danos morais ao autor, a qual arbitra-se no valor de $\mathrm{R} \$ 30.000,00$ (trinta mil reais). Recurso de revista conhecido por divergência jurisprudencial e provido. (RR-1332-08.2011.5.05.0016, Relator Ministro: Alexandre Agra Belmonte, Data do julgamento: 04/05/2016, $3^{\text {a }}$ Turma, Data da publicação DEJT: 06/05/2016). [Cursivas añadidas].

Criterio Jurídico Garantista. (Ene.-Jun. de 2017). Vol. 10, n. ${ }^{\circ}$ 16, 106-123. ISSN: 2145-3381. Bogotá: Universidad Autónoma de Colombia. 
CEO (Chief Executive Officer), a la fecha de la entrevista (2006) la empresa admitía personas bonitas, "pues ellas atraen a personas bonitas, que son el público objetivo de la empresa”. Cuando le preguntaron si la empresa era excluyente, el propio CEO afirmó: “con toda certeza” (Kaplan, 2015). Entre las medidas patronales adoptadas se destaca el uso de hombres sin camisa para atraer a clientes, la prohibición del uso del velo o hijab, y de pelos teñidos que no aparentasen naturalidad.

La práctica discriminatoria patronal sufrió una acción colectiva (class action) en 2003, bajo la acusación de que la empresa contrataba, preferencialmente, hombres blancos para posiciones de gerencia y de representación de marca. En 2005

hubo un acuerdo en la acción de clase consistente en el importe de USD 40 millones de dólares a los demandantes que dijeron haber sido preteridos de los puestos de trabajo por su condición étnica, racial o de género, y la previsión de varias medidas con el intuito de revertir el cuadro discriminatorio al interior de la empresa, incluso con la creación de un departamento de diversidad y medidas concretas para disminuir la desigualdad de funciones. ${ }^{12}$

Las diversas acciones judiciales y la presión social posibilitaron profundos cambios en la política visual y en el código de vestuario de la empresa, y es cierto que la pura alegación liberal del poder directivo del empleador de conducir su empresa en la forma que quiera encontró barreras desde el punto de vista social de no discriminación, hasta en el mismo símbolo de libre mercado en EE. UU. Es así que en 2013 la empresa reformó su política visual para permitir el hijab y otras acomodaciones por motivo religioso o de discapacidad. En 2015, Abercrombie anunció finalmente una gran transformación, afirmando que no contrataría más trabajadores en base a su atracción física, no exigiría más el uso de ropas hechas por la compañía, relajaría el código de vestuario para permitir la expresión de la individualidad de cada uno y no colocaría más hombres sin camisa para ayudar a atraer clientes (Kaplan, 2015).

Como se observa, es evidente en el caso la incursión de patrones y prejuicios sociales que pasan a ser reproducidos en el interior de los lugares de trabajo, con el fin de maximizar el lucro. Al contrario de pura "política de la empresa”, o adecuación a su público objetivo (argumentos que podrían llevar a la aceptación de la antigua situación), lo que se ve es un verdadero acto de discriminación a las trabajadoras y trabajadores como un todo, que ven sus cuerpos disciplinados para reproducir un prejuicio social, objetivándoles y negándoles autonomía.

Otro ejemplo, también extraído de los EE. UU., es el caso del restaurante Hooters, que siente orgullo de tener un ícono reconocido globalmente, las hooters girls, mujeres vestidas con shorts muy cortos de color anaranjado, contratadas para atender a los clientes en calidad de meseras. En 12. El contenido completo del acuerdo (consent decree) está disponible en: http://digitalcommons.ilr.cornell.edu/cgi/viewcontent.cg
i? article=1022\&context=condechttp://afjustice.com/pdf/20041116_consent_decree.pdf. 
1997, algunos hombres instauraron una acción colectiva en contra de la empresa, por acto discriminatorio, alegando que fueron preteridos de los puestos por su condición de hombres. La acción terminó en acuerdo en el importe de USD 3 millones de dólares y con la previsión de contratación de hombres para puestos "neutrales", pero no para atender al cliente (Shamsian, 2015). En 2009 fue presentada una nueva acción colectiva, que de nuevo terminó por medio de acuerdo. Más allá de la actitud discriminatoria de no contratar hombres para el puesto de meseros o atención al cliente, el tema es que el propio código de vestuario de la empresa ya presenta en sí mismo un acto de discriminación.

La disciplina del cuerpo se revela en el código de vestuario al aprovechar un prejuicio social ya existente, que objetiviza las mujeres en diversas instancias sociales, y lo reproduce en el lugar de trabajo, obligándolas al uso de shorts muy cortos. Lo que tenemos con ello es no solo una violación de la autonomía individual de las trabajadoras y la ofensa a su integridad física y psicológica, sino también un acto de discriminación en contra de todas las mujeres, que no bastando su exposición como un objeto sexual en revistas y en los medios, ahora se ven obligadas a asistir a la reproducción de dicho prejuicio en sus lugares de trabajo.

No es posible que el objeto social de la empresa capture la propia corporeidad de las trabajadoras. La referida conducta sobrepasa demasiado los objetivos del contrato de trabajo que, en el caso, es servir a los clientes los pedidos que se encuentran en el menú del restaurante. En este sentido, es evidente la violación a la dignidad humana, a la intimidad, al honor e imagen de las trabajadoras, y también un acto de discriminación no solo a los hombres (que en verdad es el menor de los problemas, incluso porque se podría reivindicar discriminaciones positivas en algunas instancias), que son preteridos de los puestos, sino principalmente a las propias mujeres, que son objetivadas en la relación laboral y sus cuerpos capturados para un aumento de la clientela, de la productividad y del lucro de la empresa, en detrimento de su subjetividad.

Tal como se observa, aquí también la disciplina del cuerpo puede servir de punto de referencia para el análisis de las violaciones de los derechos de las trabajadoras y trabajadores. En consecuencia, debe ser repudiado todo acto que ultrapase la pura utilización de la fuerza de trabajo y sancionado en la forma del instrumental jurídico hábil a reprimir las referidas conductas.

\section{Conclusión}

Es evidente que la disciplina de la fuerza de trabajo, por sí misma, también permite un encuadramiento de actos atentatorios a la dignidad de la trabajadora y trabajador. No se trata de negar la existencia de violaciones en el curso de la utilización de la fuerza de trabajo, sino de resaltar la posibilidad teórica de un pensamiento más objetivo de los abusos cometidos en el marco de la relación laboral.

Una hipótesis es la identificación de la disciplina del cuerpo en las relaciones laborales. Más allá de la casuística o de la ponderación de principios, la incursión del poder directivo sobre el cuerpo 
de la trabajadora o trabajador, por sí misma, ya permite la identificación de la violación a la dignidad humana o una ofensa a la intimidad, la vida privada, el honor o la imagen de las personas, particularmente por tratarse de elementos que exceden el objeto del contrato de trabajo, que es la compra y venta de la fuerza de trabajo y no del cuerpo.

De hecho, una comprensión democrática de las relaciones sociales no permite un abordaje absoluto de los actos directivos del empleador. El proceso productivo capitalista, sin embargo, no ve límites. Si la apropiación del cuerpo se muestra rentable, habrá el intento de sumisión y expropiación de este elemento.

122 En este sentido, identificada la incursión o el intento de incursión del empleador sobre el cuerpo de la trabajadora o trabajador, sea por medio del reglamento de la empresa, el código de vestuario, la política de vigilancia abusiva, la política de contratación o despido discriminatoria, estará configurado el uso abusivo del poder directivo, debiendo incidir en el caso las normas de protección a los derechos humanos en las relaciones laborales, particularmente desde su eficacia horizontal, es decir, entre las partes del contrato de trabajo.

\section{Referencias}

Brasil. Constituição da República Federativa do Brasil de 1988. Obtenido de planalto: http:/ / www.planalto.gov.br/ccivil_03/constituicao/ constituicaocompilado.htm
Brasil. Consolidação das leis do trabalho - DecretoLei $n .^{\circ}$ 5.452, de $1^{\circ}$ de maio de 1943. Obtenido de planalto: http://www.planalto.gov.br/ ccivil_03/decreto-lei/Del5452.htm

Brasil. MTE. Norma regulamentadora $n .{ }^{\circ} 17-$ Anexo II - Portaria SIT $n .{ }^{\circ}$ O9, de 30 de março de 2007. Obtenido de acesso: http://acesso. mte.gov.br/data/files/FF8080812BE914E6012BEFBAD7064803/nr_17.pdf

Delgado, M. G. (2014). Curso de Direito do Trabalho. (Décimo terceiro Ed.). São Paulo: LTR.

Ferdman, R. A. (11 may, 2016). 'I had to wear Pampers': The cruel reality the people who bring you cheap chicken allegedly endure. The Washington Post. Recuperado el 10 de agosto de 2016 de whashingtonpost: https:// www.washingtonpost.com/news/wonk/ wp/2016/05/11/i-had-to-wear-pampersmany-poultry-industry-workers-allegedlycant-even-take-bathroom-breaks / \#comments.

Foucault, M. (1987). Vigiar e punir: nascimento da prisão (R. Ramalhete, Trad.). Petrópolis: Vozes.

Kaplan, S. (2 june, 2015). The rise and fall of Abercrombie's 'look policy'. The Washington Post. Obtenido de washingtonpost:: https:// www.washingtonpost.com/news/morningmix/wp/2015/06/02/the-rise-and-fall-ofabercrombies-look-policy/.

Maneghetti, G. y Sampaio, S. S. (janeiro-junho, 2016). A disciplina como elemento constitutivo do modo de produção capitalista. Katálise, 19(1), 135-142. 
Marx, K. (2013). O capital: crítica da economia política: Livro I: o processo de produção do capital (R. Enderle, Trad.). São Paulo: Boitempo.

Mascaro, A. L. (2012). Curso de Filosofia do Direito. (Segunda Ed.). São Paulo: Atlas.

Netto, J. P. y Braz, M. (2012). Economia Política: uma introdução crítica. (Oitava Ed.). São Paulo: Cortez.
Shamsian, J. (13 september, 2015). The strange loophole that lets Hooters hire only female servers. Business Insider. Obtenido de businessinsider:: http://www.businessinsider.com/how-can-hooters-hire-onlywomen-2015-9.

Souto Maior, J. L. (2011). Curso de Direito do Trabalho. Teoria Geral do Direito do Trabalho. Vol. I. Parte 1. São Paulo: LTR. 